\title{
Eddy covariance flux tower: a promising technique for greenhouse gases measurement
}

\begin{abstract}
Anthropogenic activities have released huge amounts of greenhouse gases namely carbon dioxide, methane and nitrous oxide into the atmosphere. Buildup of greenhouse gases into the atmosphere causing climate change and it result in several dangerous effects to ecosystems functioning, human health and welfare. Over the past century we witnessed faster changing climate and it is going to be faster, if proper measures for its mitigation is not adopted. For effective mitigation of anthropogenic emission of these Greenhouse gases, it is really important to know the current total GHG emission and that is to at precisely. For measurements of GHGs emission two techniques are common namely closed chamber techniques and eddy covariance techniques. Till today, the closed chamber technique is the most popularly used. In this, emissions of gases from soil are usually determined by closed chamber placed over the soil surface, which restricts the volume of air exchange across the covered surface. Eddy covariance flux tower is the micrometeorological method which continuously measures the vertical concentration gradients of the gases. The present article is focused on the measurement of GHGs using eddy covariance flux tower and its importance over the closed chamber techniques.
\end{abstract}

Volume 7 Issue 4 - 2017

\author{
Kumar A,' Bhatia A,' Fagodiya RK,' Malyan \\ SK,' Meena BL' \\ 'Center for Environment Science and Climate Resilient \\ Agriculture, ICAR-Indian Agricultural Research Institute, India \\ ${ }^{2}$ Project Coordinating Unit, ICAR-Central Soil Salinity Research \\ Institute, India
}

\begin{abstract}
Correspondence: Kumar A, Center for Environment Science and Climate Resilient Agriculture, ICAR Indian Agricultural Research Institute, New Delhi I 32 00I, India,
\end{abstract}

Email amit_bio80@yahoo.com

Received: June 19,2017 | Published: August 24, 2017

Keywords: eddy covariance, closed chamber technique, flux, greenhouse gas

Abbreviation: $\mathrm{CH}_{4}$, methane; $\mathrm{CO}_{2}$, carbon dioxide; $\mathrm{EC}$, eddy covariance; GC-FID, gas chromatography fitted flame ionization detector; $\mathrm{GHG}$, greenhouse gases; $\mathrm{H}_{2} \mathrm{O}$, water; IR, infrared radiation; IRGA, infra red gas analyzer; $\mathrm{N}_{2} \mathrm{O}$, nitrous oxide; PAR, photo synthetically active radiation; UV, ultra violet radiation

\section{Introduction}

The Earth receives short wave radiation (UV, visible, and near IR) and emits back the long wave radiation (thermal infrared). Most of these thermal radiation emitted by earth surface is absorbed by the atmospheric green house gases (GHGs) and is reradiated in all direction. This natural phenomenon of radiation trapping is known as greenhouse effect and it is responsible for increasing earth's temperature. ${ }^{1}$ The earth's surface is naturally warmed by solar energy as it receives directly. However, with the industrial revolution particularly in ninetieth century, a huge amount of GHGs are being emitted annually to the atmosphere due to industrial activities, fossil fuel combustion, widespread deforestation, burning of biomass, land-use change and land management practices. ${ }^{1}$ This phenomenon of increasing GHGs concentration worries the global scientific community, because it would increase the average earth surface temperature beyond $15^{\circ} \mathrm{C}$. This phenomenon is popularly termed as 'enhanced greenhouse effect. To distinguish enhanced greenhouse effect from the natural greenhouse effect has been taking place for centuries. Most of anthropogenic emission of GHGs comes from industrial activities, besides this intensive agriculture and change in land use also contributed significantly to GHGs emission. ${ }^{2-6}$ The carbon dioxide $\left(\mathrm{CO}_{2}\right)$ is important and main GHG contributing to global warming, which is principally emitted as a result of anthropogenic activity. The global atmospheric concentrations of $\mathrm{CO}_{2}$, methane $\left(\mathrm{CH}_{4}\right)$ and nitrous oxide $\left(\mathrm{N}_{2} \mathrm{O}\right)$ have increased markedly due to human activities. ${ }^{7}$ This is really important to estimate the net warming potential of GHG emission from agriculture. ${ }^{8,9}$ In this context eddy covariance flux tower could be a very useful technology.

\section{Greenhouse gas emission and its measurement}

For the quantification of GHGs sources and sinks, the measurements of GHGs are essential. Two methods are being used to measure GHG emission from soils namely soil chambers (closed chamber technique) and micro-meteorological technique (Figure 1). Till now the closed chamber techniques is the most popular and preferred method used for GHG measurement from the agricultural soils. In this, emissions of gases from soil are usually determined by measuring the short-term buildup emitted gas in a closed chamber placed over the soil surface. This restricts the volume of air exchange across the covered surface. Any net emission or uptake of gas from soil is measured as a change in its concentration. On the other hand the Micrometeorological method measures the vertical concentration gradients of the gas using eddies covariance..$^{10}$ Now a day the eddy covariance technique is being preferred over the close chamber due to higher precision and its ability to measure continuous flux over large agricultural area. ${ }^{11}$ Eddy covariance based GHG flux tower gives the continuous measurement over larger area with detail information on short-term variation of flux, having high precision with high sampling rate and short response time. Whereas, the closed chambers measurements of greenhouse gas flux are short term measurements and are restricted to a limited area of measurement. The major demerit of eddy covariance flux tower over close chamber technique is its high cost (Table 1).

\section{Eddy covariance flux tower}

Eddy covariance flux: Flux is the total amount of air moves through a unit area in a unit time and it is the mean product of the vertical wind speed and the value of the property. It depends on several properties viz. crossing area, size of area of interest being crossed and time takes to cross the interest. The accuracy of eddy covariance depends on several factors and it is most accurate in steady atmosphere, homogenous underlying vegetation and when it is situated on flat terrain. 
Principle of Eddy covariance: Eddy covariance requires measurements of 3-dimensional (3D) wind speed and gas concentration. Air flow is imagined as a horizontal flow of several rotating eddies, which are, turbulent vortices of various sizes, with each eddy having both horizontal and vertical components. These vertical components can be measured from the tower (Figure 2). Air flow can be pictured as a horizontal flow of eddies, as 3D structures bringing different properties of surface and environmental (partial gas concentration, temperature and humidity) with them. For accurate determination of the air flux the high speed and precision instruments are most critical for rapid measurement of all the small changes in the air samples.

Physical meaning of the eddy covariance method: Suppose on an eddy covariance tower, at point- 1 and time- 1 , the eddy- 1 moves the parcel of air c-1 down at the speed of $w-1$. Then, at point-2 and time-2, the eddy-2 moves parcel of air c-2 up at the speed of w-2. ${ }^{13}$ Each air parcel moves having gas concentration, temperature, and humidity. The air flux can be calculated by knowing these factors, along with the known speed of air. Therefore, vertical flux can be presented as a covariance of the vertical wind velocity and the concentration of the entity of interest. ${ }^{13}$

Components of eddy covariance system: The important components of the eddy covariance flux tower are mentioned in Figure 1B. It has three dimensional sonic anemometers which measure the wind direction and its speed. Is has sensors for nitrous oxide $\left(\mathrm{N}_{2} \mathrm{O}\right)$ methane $\left(\mathrm{CH}_{4}\right)$ carbon dioxide $\left(\mathrm{CO}_{2}\right)$ and water vapor $\left(\mathrm{H}_{2} \mathrm{O}\right)$ along with sensors for measurements incoming and outgoing, short wave and long wave radiation and photo synthetically active radiation (PAR). Other sensors for measurement of air temperature, relative humidity and heat flux are also the important. The sensors for soil moisture and temperature measurement can be installed at varying depths of $0-90 \mathrm{~cm}$ to monitor soil moisture and temperature from different depth of soils. A rain gauge is also associated to measure the precipitation. All data from the sensors are stored in the data logger and also in the flash card which can be replaced after transferring the data to the computer. The flash card should be formatted once the data is transferred. The eddy covariance requires continuous power supply for uninterrupted day night operation. To fulfill this requirement solar panels are installed in field on the flux tower tripod that charge the battery. The system operates on $5-20 \mathrm{~Hz}$ frequency measuring data point of the different parameters 5-20times in 1second.

Calculation of fluxes: The three dimensional wind speeds from sonic anemometer and other variables, usually gas concentration, temperature or momentum are decomposed into mean and fluctuating components. By finding the covariance between the vertical wind speed fluctuations with fluctuation in temperature, humidity, carbon dioxide, methane, sensible and latent heat etc., fluxes of these variables are determined. ${ }^{14-16}$ The covariance is calculated between the fluctuating component of the vertical wind and the fluctuating component of gas concentration. The Eddy Covariance is a non-destructive, continuous technique for automatic measurement of GHGs fluxes, moisture and heat from large area at very short-term intervals. The eddy covariance flux tower is mathematically complex, and requires significant care in setting up and processing data. The Corrections for density fluctuations, ${ }^{16}$ are required to perform for variations in temperature and water vapor. The coordinate rotation correction is carried out by following Kaimal et al. ${ }^{14}$ Sonic temperature correction for humidity was applied as per Van Dijk et al. ${ }^{17}$ The time lag compensations due to the sensor separations between sonic anemometer and gas sensor were applied as per Fan et al. ${ }^{18}$ The quality control of eddy covariance flux data is further required. ${ }^{19}$ The flux footprint (measurement of the cumulative normalized contribution to the surface flux from the upwind location) can also be check. ${ }^{20}$ This EC technique also allows for direct measurement of scalar and energy fluxes at the surface, and is the chief flux data collection method utilized by many continentalscale networks such as Ameri Flux, Euro Flux, Fluxnet Canada, Oz Flux, and Asia Flux. Data from EC stations can be used to quantify annual carbon and water balances from an ecosystem on a watershed scale, and such data can be utilized for flux measurement, model parameterization, remote sensing and ground-truth comparisons for regional models. ${ }^{21}$ Eddy covariance can be deployed for long periods of time to evaluate and predict annual ecosystem responses. Such topics are incredibly relevant to building a foundation for the mutual well-being of the environment and its inhabitants. As the exchange of energy and mass between the surface and the atmosphere is a fundamental process that controls the environment in which life operate. The complex nature of this transport is essential to understand, and such data presents countless opportunities for assessing ecosystem productivity, sustainability, or other important environmental topics.

Comparison between closed chamber and eddy covariance: There are several techniques for GHGs measurement from field and depending upon goal of study and available resources, one can chose suitable technique. Two important techniques for GHGs measurements are a) closed chamber techniques and b) eddy covariance flux techniques (Figure 1A) (Figure 1B). The scale of measurement, relative advantages and limitations of close chamber techniques in comparison of eddy-covariance are presented in Table $1 .{ }^{22}$

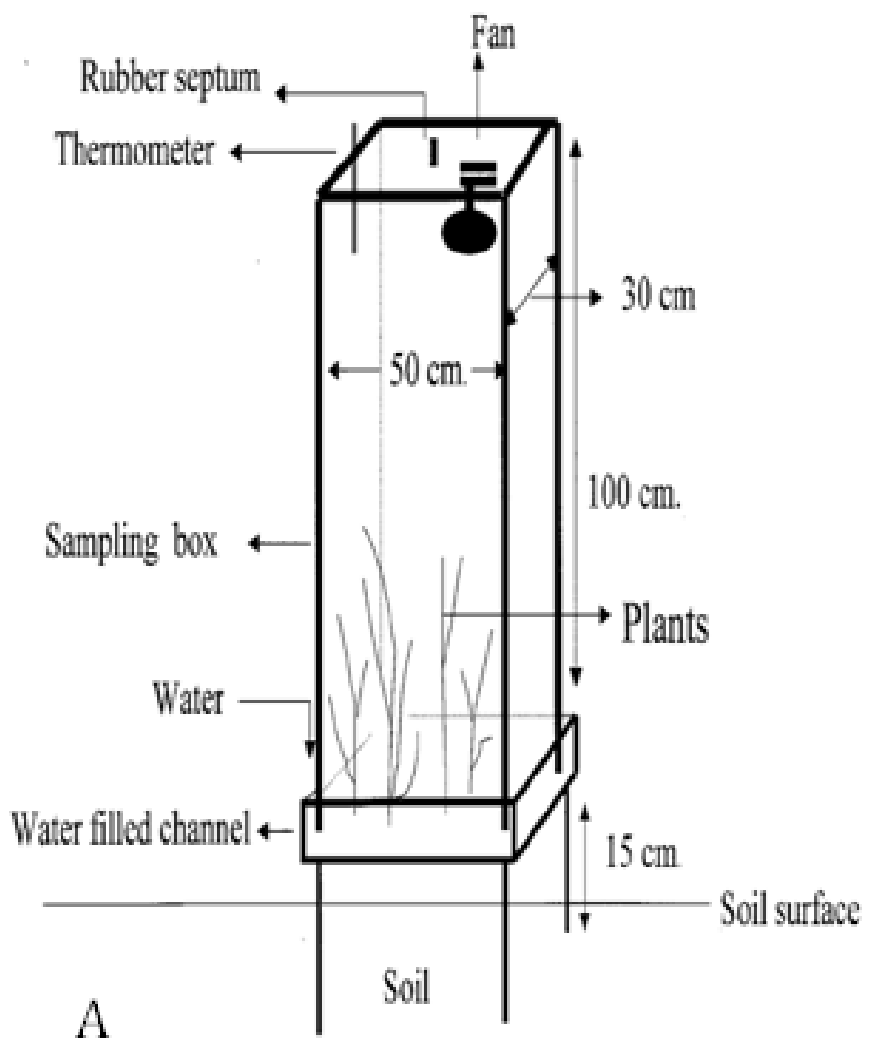

Figure IA Close Chamber [Source: 12]. 


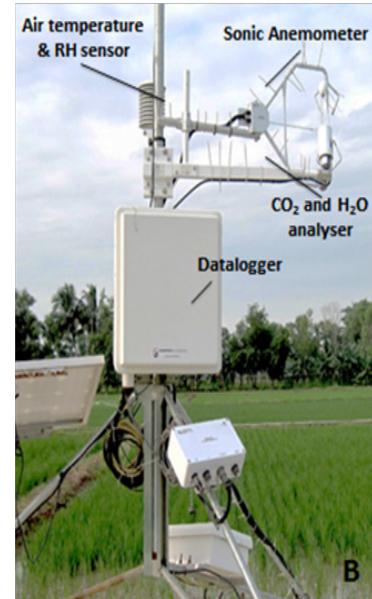

Figure IB Eddy Covariance technique [Source: I0].

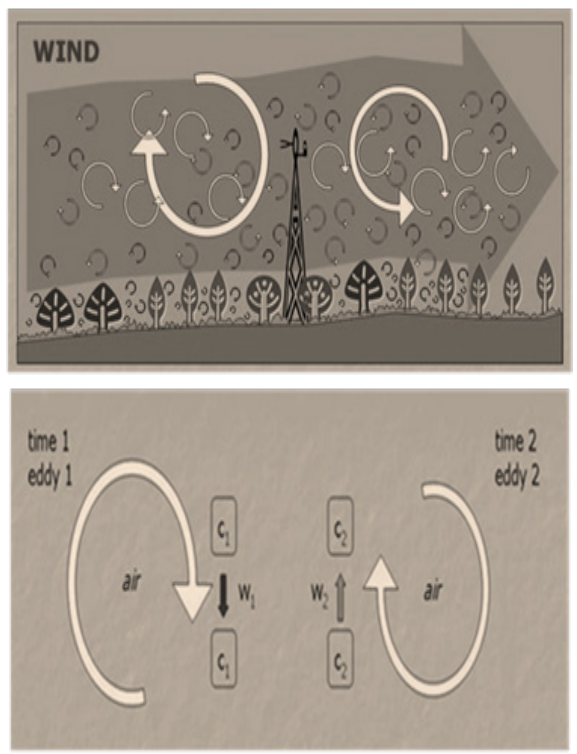

Figure 2 Air flow in the atmospheric boundary layer. ${ }^{13}$

Table I Comparison of different measuring techniques to determine GHG emission

\begin{tabular}{lll}
\hline Parameters & $\begin{array}{l}\text { Closed chamber } \\
\text { techniques }\end{array}$ & $\begin{array}{l}\text { Eddy covariance } \\
\text { techniques }\end{array}$ \\
\hline $\begin{array}{l}\text { Scale of } \\
\text { measurement }\end{array}$ & Small & Large \\
$\begin{array}{l}\text { Area of } \\
\text { measurement }\end{array}$ & $<1 \mathrm{~m} 2$ & $>100$ \\
Analyzer & GC-FID & IRGA \\
& $\begin{array}{l}\text { Useful for measurement } \\
\text { of small flux }\end{array}$ & $\begin{array}{l}\text { No or minimum } \\
\text { distribution }\end{array}$ \\
& $\begin{array}{l}\text { No or limited energy } \\
\text { required }\end{array}$ & $\begin{array}{l}\text { Can measure ecosystem } \\
\text { basis fluxes }\end{array}$ \\
& $\begin{array}{l}\text { Good for short duration } \\
\text { collection sampling periods seasonal variations }\end{array}$ & $\begin{array}{l}\text { Useful for diurnal and } \\
\text { Advantage }\end{array}$ \\
& Low manufacturing cost & \\
\hline
\end{tabular}

Table Continued.

\begin{tabular}{lll}
\hline Parameters & $\begin{array}{l}\text { Closed chamber } \\
\text { techniques }\end{array}$ & $\begin{array}{l}\text { Eddy covariance } \\
\text { techniques }\end{array}$ \\
\hline $\begin{array}{l}\text { Build up gases } \\
\text { concentrations } \\
\text { in chamber }\end{array}$ & $\begin{array}{l}\text { No or minimum } \\
\text { distribution }\end{array}$ \\
$\begin{array}{l}\text { Alter the atmospheric Temp. } \\
\text { and pressure which may } \\
\text { inhibit the normal emission analysis is difficult } \\
\text { rate of soil }\end{array}$ & $\begin{array}{l}\text { Required continuous } \\
\text { energy supply }\end{array}$ \\
Disadvantage & $\begin{array}{l}\text { High level of assumption } \\
\text { and correction }\end{array}$ \\
& & $\begin{array}{l}\text { Dependence on } \\
\text { atmospheric conditions }\end{array}$ \\
\hline
\end{tabular}

\section{Conclusion}

The eddy covariance flux tower provides the both quantitative and qualitative data continuous basis data that is to with high accuracy and less uncertainty. However, it is comparatively costly technique and required skill person for its operation and data recording than the closed chamber technique.

\section{Acknowledgements}

None.

\section{Conflict of interest}

The author declares no conflict of interest.

\section{References}

1. IPCC. The Physical Science Basis: Working Group I Contribution to the Fifth Assessment Report of the Intergovernmental Panel on Climate Change. USA: Cambridge University Press; 2013.

2. Bhatia A, Kumar A, Kumar V, et al. Low carbon option for sustainable agriculture. Indian Farming. 2013;63(2):18-22.

3. Gupta DK, Bhatia A, Kumar A, et al. Mitigation of greenhouse gas emission from rice wheat system of the Indo Gangetic plains:through tillage, irrigation and fertilizer management. Agric Ecosyst Environ. 2016;230:1-9.

4. Gupta DK, Bhatia A, Kumar A, et al. Global warming potential of rice (Oryza sativa)-wheat (Triticum aestivum) cropping system of the IndoGangetic Plains. Indian J Agric Sci. 2015;85(6):807-816.

5. Bhatia A, Kumar A, Das TK, et al. Methane and nitrous oxide emissions from soils under direct seeded rice. IJASS. 2013;9(2):729-736.

6. Fagodiya RK, Pathak H, Bhatia A, , et al. Simulation of Maize (Zea Mays L.) Yield Under Alternative Nitrogen Fertilization Using Infocrop-Maize Model. Biochem Cell Arch. 2017;17(1):65-71.

7. Kumar A, Tomer R, Bhatia A, et al. Greenhouse Gas Mitigation in Indian Agriculture published in Agro-Technologies for Adaptation to Climate Change. In: Pathak H, et al. editors. India; 2016.

8. Fagodiya RK, Pathak H, Meena BL, et al. Need to estimate the net global warming potential of nitrogenous fertilizers. Adv Plants Agric Res. 2017;6(4):1-2 
9. Fagodiya RK, Pathak H, Kumar A, et al. Global temperature change potential of nitrogen use in agriculture: A 50-year assessment. Sci Reports. 2017;7:44928.

10. Bhattacharyya P, Mohanty S, Sarkar RK, et.al. Measurement of Integrated greenhouse gas flux with eddy covariance technique published in Measurement of greenhouse gas emission from crop, livestock and aquaculture. In: Pathak H, editor. India; 2013. p. 15-25.

11. Bhatia A, Jain N, Kumar A, et al. Monitoring fluxes of greenhouse gas, moisture and heat in agriculture with Eddy covariance flux tower" published in Climate Change Impact, Adaptation and Mitigation: Methodology for Assessment and Applications. In: Pathak H editor. India; 2011. p. $34-48$.

12. Bhatia A, Jain N, Bhattacharyya P, et al. Measurement of Greenhouse Gas Emissions from Crop Fields published in Measurement of greenhouse gas emission from crop livestock and aquaculture. In: Pathak $\mathrm{H}$ editor. India; 2013. p. 6-14.

13. Burba G, Anderson D. A Brief Practical Guide to Eddy Covariance Flux Measurements: Principles and Workflow Examples for Scientific and Industrial Applications. Lincoln, USA: LI-COR Biosciences; 2010. p. $1-211$.

14. Kaimal JC, Finnigan JJ. Atmospheric Boundary Layer Flows. USA: Oxford University Press; 1994. p. 1-289.
15. Tanner CB, Thurtell GW. Anemoclinometer Measurements of Reynolds Stress and Heat Transport in the Atmospheric Surface Layer. ECOM, USA: University of Wisconsin Tech Rep; 1969. p. 1-82.

16. Webb EK, Pearman, GI, Leuning R. Correction of flux measurements for density effects due to heat and water vapour transfer. $Q J R$ Met Soc. 1980;106(447):85-100.

17. Van Dijk A, Kohsiek W, de Bruin HAR. The principles of surface flux physics: theory, practice and description of the ECPACK library. Meteorology and Air Quality Group; 2004. p. 1-99.

18. Fan SM, Wofsy SC, Bakwin PS. Atmosphere biosphere exchange of $\mathrm{CO}_{2}$ and $\mathrm{O}_{3}$ in the central Amazon forest. $J$ Geophys Res. 1990;95(D1020):16851-16864.

19. Foken Th, Wichura B. Tools for quality assessment of surface-based flux measurements. Agric For Meteorol. 1996;78(1-2):83-105.

20. Schuepp PH, Leclerc MY, MacPherson JI, et al. Footprint prediction of scalar fluxes from analytical solutions of the diffusion equation. Boundary Layer Meteorol. 1990;50(1-4):355-373.

21. Mizoguchi Y, Miyata A, Ohtani Y, et al. A review of tower flux observation sites in Asia. J For Res. 2009;14(1):1-9.

22. Malyan SK, Bhatia A, Kumar A, et al. Methane production, oxidation and mitigation: A Mechanistic understanding and comprehensive evaluation of influencing factors. Sci Total Environ. 2016;572:874-896. 